\title{
Hombres de la villa y hombres de fuera de la villa en Piera durante la Baja Edad Media
}

\author{
Flocel Sabaté
}

PALABRAS CLAVE: enfiteusis, fiscalidad, manso, Edad Media.

\section{CÓDIGOS JEL: R220, R280, H230, N5.}

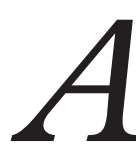
nálisis de la documentación inédita sobre Piera (Cataluña) entre los siglos $X$ $y \mathrm{XV}$ para interpretar la organización bajomedieval de los hombres de fuera de la villa contra los hombres de la villa en temas fiscales y defensivos. El paisaje agrario, creado en la Alta Edad Media donde se ubicaba el desordenado espacio de frontera, perfila, en los siglos XII y XIII, un incremento del espacio cultivado con la creación de mansos en enfiteusis, y con cenobios e inversores urbanos acumulando dominio directo. Esto facilita la presión exactiva de los propietarios sobre los campesinos en el paso del siglo XIII al XIV, que da lugar a la primera queja ante el rey de los hombres de fuera de la villa contra los hombres de la villa. Se repetirá poco después con respecto a la distribución interna de las exigencias fiscales de la Corona, y aun en la segunda mitad del siglo respecto del sistema defensivo. Las dificultades en la segunda mitad de siglo XIV evidencian la inviabilidad de muchos de los mansos creados en la centuria precedente y contribuyen a la acumulación de propiedades por parte de la élite urbana inversora. La incidencia urbana sobre el campo-por la propia villa y por la burguesía de Barcelona y su monasterio de Pedralbes- propicia una fuerte presión en el siglo XV, la anulación de la capacidad organizativa rural y un malestar que impone la reducción negociada de la carga exactiva. 


\section{Townsmen of Piera and men from outside the town in the Late Middle Ages}

\section{KEYWORDS: emphyteusis, taxation, farm, Middle Ages.}

\section{JEL CODES: R220, R280, H230, N5.}

nalysis of the unpublished documentation about Piera (Catalonia) between
the $10^{\text {th }}$ and $15^{\text {th }}$ centuries to interpret the late-medieval organisation of the
"man from outside the town" against the "men of the town" in fiscal and defensive matters. The agrarian landscape created in $10^{\text {th }}-11^{\text {th }}$ centuries where the disorganised frontier area was, saw an increase in the farmed area in the $12^{\text {th }}$ and $13^{\text {th }}$ centuries, creating farms in emphyteusis and with monasteries and urban investors accumulating direct domain. This increased tax burden on the peasants by the owners at the end of the $13^{\text {th }}$ and early $14^{\text {th }}$ centuries, led to the first complaint to the king by the men from outside the town against the men of the town. This would be repeated shortly after regarding the internal distribution of the Crown's fiscal demands and in the second half of the century, for the defensive system. The difficulties arisen in the second half of the $14^{\text {th }}$ century show the unviability of many of the farms created in the previous century and contributed to the accumulation of property among the urban investing elite. The urban influence on the countryside -for the town itself and for the bourgeoisie of Barcelona and their monastery of Pedralbes-favoured heavy pressure in the $15^{\text {th }}$ century, the nullification of the rural capacity for organisation and a malaise that led to the negotiated reduction in the tax burden.

Recepción: 2020-05-15 - Revisión: 2020-11-21 - Aceptación: 2020-11-21

Flocel Sabaté [orcid.org/0000-0001-7312-1119] es catedrático de Historia Medieval en la Universidad de Lleida. Dirección para correspondencia: Departament d'Història. Facultat de Lletres, Universitat de Lleida, PlaçaVictor Siurana, 1, 25003 Lleida.C.e.flocel.sabate@udl.cat 


\section{INTRODUCCIÓN}

Las tensiones territoriales se suelen situar, en el espacio bajomedieval catalán, entre las capitales y su región de influencia. En cambio, en el caso de Piera se acentúa una tensión dentro del propio término, entre la villa y el espacio rural, hasta el punto de organizarse, en los siglos XIII y XIV, una protesta de los hombres de fuera de la villa contra los hombres de la villa, especialmente por el reparto fiscal. Su análisis nos muestra, por un lado, la formación de la renta en la intersección entre el espacio rural y el urbano y, por otro, la apropiación del ámbito rural por las élites de la villa ${ }^{1}$.

\section{SINGULARIZACIÓN EN EL MARCO DEL ESPACIO BAJOMEDIEVAL}

En la Cataluña bajomedieval la unidad jurisdiccional y fiscal básica es el distrito castral, conocido como castillo termenado (Pons, 1989-2006: vol. 3, 341-351). Sobre esta base, la articulación del territorio parte de la irradiación social y económica de los núcleos urbanos sobre su entorno. La extensión de las regiones socioeconómicas es directamente proporcional al auge del centro rector. Las unidades administrativas bajomedievales, como las veguerías, alcanzan el grado de operatividad y perdurabilidad cuando concuerdan con estas capitalidades y estos radios socioeconómicos previamente existentes. La relación entre la población central y el espacio de la región se teje gracias a los atractivos propios de un centro de servicios y, sobre todo, a través de los lazos establecidos por la cúpula urbana, la cual interpreta el entorno como su ámbito de inversión, por lo que trata de acaparar y gestionar tierras y derechos de variada procedencia. La población de la región resta fácilmente vinculada mediante obligaciones censuales y crediticias, mientras que la producción agropecuaria se imbrica con la especulación de las élites urbanas.

Ligada por estos intereses, la región es asumida como elemento propio del centro rector, que trata de incidir en todos los asuntos de jurisdicción y representación. Las invocaciones al bien común de todos los habitantes de la demarcación no limitan una política orientada a satisfacer en primer lugar las pretensiones del propio colectivo urbano. Si hace falta se impone una legislación que supedite a los habitantes del entorno rural a las necesidades del núcleo rector en aspectos básicos como el abastecimiento de alimentos o el acceso o la provisión de leña de los bosques. Estas obligaciones crean desconfianza

1. Proyecto de investigación «El poder vivido en la Baja Edad Media: Percepción, representatividad y expresión en la gestión y la recepción del poder» (PID2019-104085GB-I00). La fragmentación, dispersión y diversidad de fuentes documentales ha permitido elaborar una base de datos de 2.058 documentos de tipología señorial, notarial, judicial, cancilleresca, parroquial, diocesana y patrimonial (tanto patrimonio regio como particular), cuyo análisis nutre el presente artículo. 
en el entorno rural, incrementada en la segunda mitad del siglo XIV cuando, ante la alarma por invasiones armadas, los centros rectores presionan para que la población rural se acoja al refugio de la muralla urbana, aportando siempre sus propias provisiones. Así se combinan vínculos de atracción con episodios de tensión, incluso cuando se comparte una misma jurisdicción.

La identificación con la región explica que las capitales urbanas negocien entre ellas para precisar sus respectivos radios de influencia; que se vayan concatenando y jerarquizando verdaderas redes urbanas; y que una misma jurisdicción sea ejercida por diferentes oficiales dentro de la demarcación cuando así lo requiere el reconocimiento de capitalidades menores. La proyección urbana sobre la región basa el prestigio de la ciudad o villa y, sobre todo, fundamenta los intereses de su élite. Por ello, la cesión de patrimonio con que el rey trata de compensar sus débiles arcas, especialmente en el siglo XIV, incrementa una infranqueabilidad jurisdiccional que colisiona con los radios de capitalidad urbana, razón por que los gobiernos municipales presionan al soberano para que adopte medidas de reintegración patrimonial.

Es un escenario distinto a otros territorios peninsulares donde la inicial estructuración espacial en amplios conjuntos territoriales en torno a una gran ciudad propicia tensiones entre el centro urbano y las aldeas (Corral, 1984: 87-88). La particularidad de Piera en el marco catalán es que, debido a la extensión de su término y la distribución del hábitat, también plantea una dualidad entre la villa y el propio espacio rural, estableciendo un duelo que, en realidad, refleja la evolución social bajomedieval. El castillo termenado de Piera está estabilizado desde mediados del siglo XI en 57,5 kilómetros cuadrados, que incluyen, por un lado, un centro urbano en torno al castillo, de rápido crecimiento (ocupa la sagrera alrededor de la iglesia y genera núcleos fuera murallas) e inmediata función comercial; y, por otro lado, el desarrollo de núcleos menores prósperos por la actividad agropecuaria en la fértil y bien comunicada llanura fluvial (El Freixe, El Bedorc, Sant Jaume de Sesoliveres, La Fortesa, Santa Creu de Creixà) y una elevada presencia de hábitats dispersos que la documentación denomina mansos $^{2}$ (Mapas 1, 2, 3 y 4).

2. Ante la necesidad historiográfica de precisar y estabilizar el contenido del término manso (DONAT et al., 2001: 127-158), aquí nos ceñimos a los usos explícitos de esta denominación por la documentación, que en todos los casos comporta una unidad de explotación agraria con un espacio de hábitat inicialmente ocupado. 


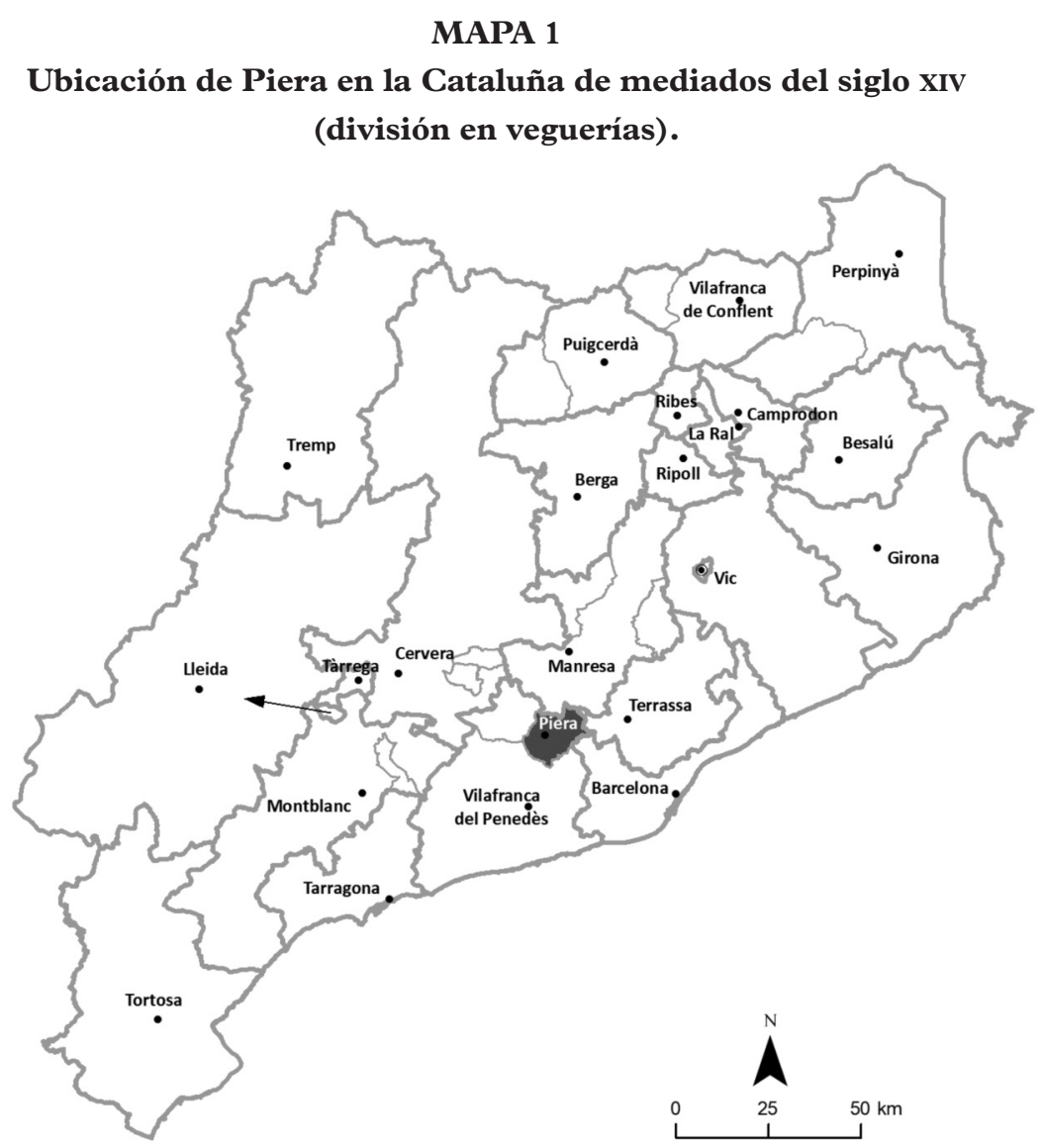

Fuente: Flocel Sabaté y Servei Cientificotècnic de Cartografia i Sistemes d'Informació Geogràfica de la Universitat de Lleida.

\section{CONSTRUCCIÓN DEL ESPACIO AGRARIO}

La organización del espacio agrario por el ser humano en la Edad Media siempre es social (García de Cortázar, 1988), pero también ideológica, porque refleja los valores con que el ser humano se relaciona con la naturaleza (Falvey, 2005: 32-35). La agricultura es el instrumento simbólico para la transformación del desorden en orden que asume como misión la Iglesia primitiva y altomedieval ${ }^{3}$, estableciendo un nexo imaginario en-

3. Ambrosius Mediolanensis, De officis ministrorum, Patrologia latina Database, vol. 16, col. 69; Hieronymus Stridonensis, Epistolae, Patrologia latina Database, vol. 22, col. 854; Agustinus Hipponensis, De doctrina Christiana, Patrologia latina Database, vol. 34, col. 57; Agustinus Hipponensis, De catechizandis rudibus, Patrologia latina Database, vol. 40, col. 336. 


\section{MAPA 2}

Subveguería de Piera en la baja edad media.

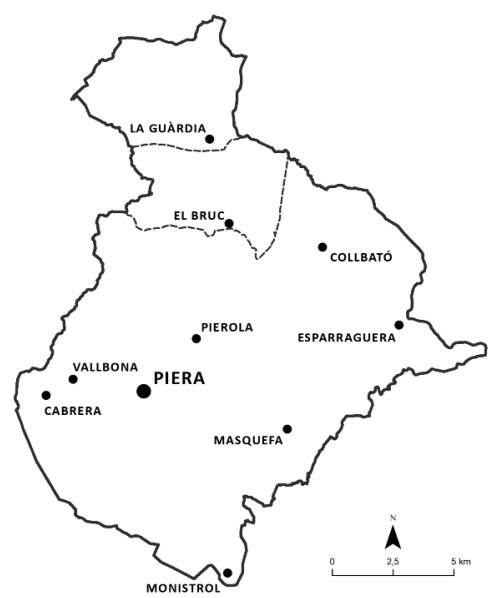

Fuente: Flocel Sabaté y Servei Cientificotècnic de Cartografia i Sistemes d'Informació Geogràfica de la Universitat de Lleida.

\section{MAPA 3}

Término de Piera medieval. Núcleos y comunicaciones.

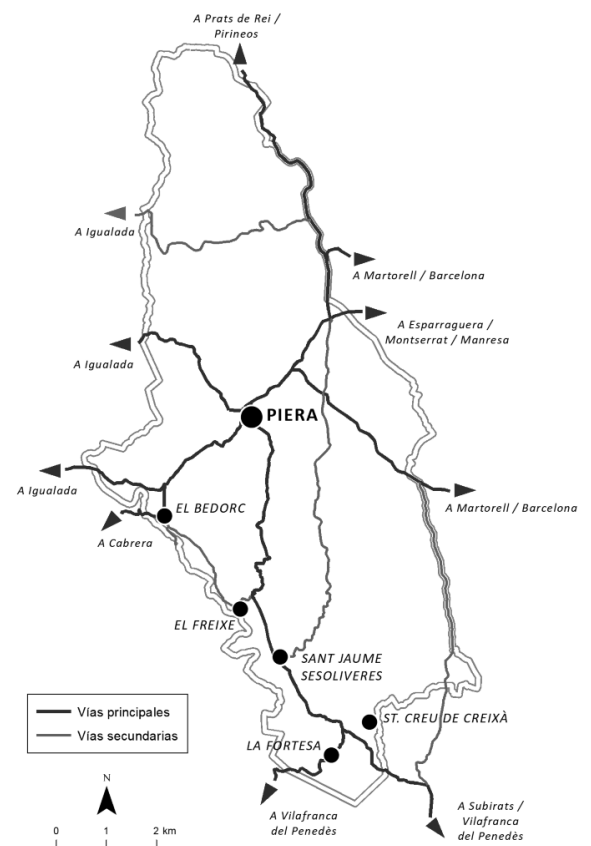

Fuente: Flocel Sabaté y Servei Cientificotècnic de Cartografia i Sistemes d'Informació Geogràfica de la Universitat de Lleida. 


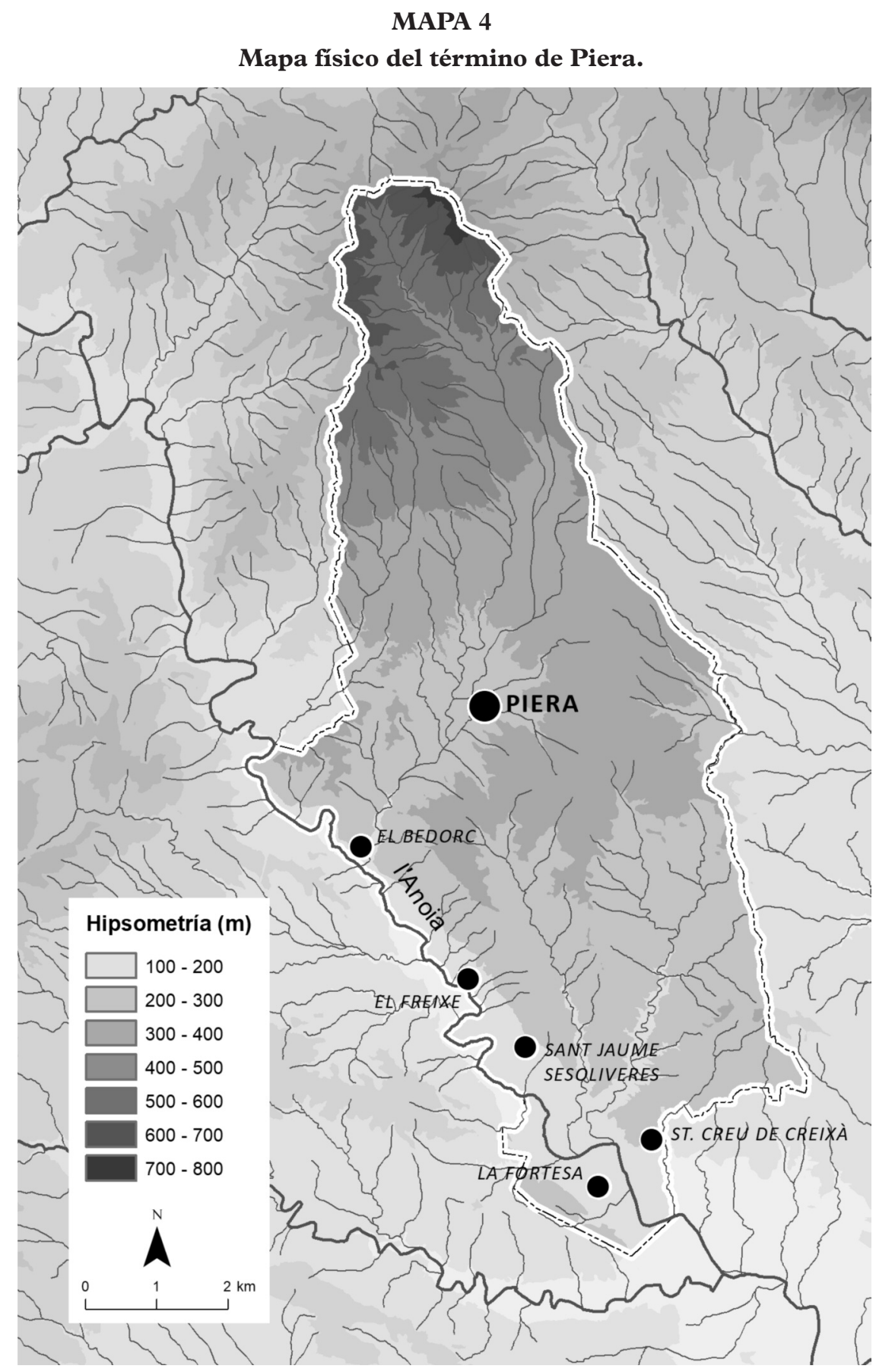

Fuente: Flocel Sabaté y Servei Cientificotècnic de Cartografia i Sistemes d'Informació Geogràfica de la Universitat de Lleida. 
tre espiritualidad y naturaleza ${ }^{4}$. El cristianismo coetáneo certifica que el destino de la naturaleza es el desarrollo agrario, bajo un nítido orden social (Jenkins, 2008: 116-132; Attfield, 2006: 76-78). Se ampara así la ocupación, por parte de la jerarquía eclesiástica y los linajes vizcondales y vicariales, del espacio desorganizado en la frontera al oeste de los condados frente al territorio andalusí y la inmediata atracción de campesinos: «ex heremo ad culturam perduxerunt» (año 996) (Junyent, 1987: 514). De este modo, en el siglo x los vizcondes de Barcelona se apropian de una extensa franja extendida entre la vertiente meridional de Montserrat y el bajo valle del rio Anoia, que se irá fragmentando en diversos términos castrales hasta restar estabilizada a mediados del siglo XI (Sabaté, 1999: 118120). En estos momentos la frontera se ha alejado de esta zona para identificarse con la marchia extrema, donde la expansión ya nítidamente feudal golpea la taifa leridana. Mientras, en Piera se incrementa el espacio agrario, se extiende el cereal, se incentiva destacadamente la viña mediante la complantatio y, en definitiva, se participa del vigor agropecuario que caracteriza todo el Penedés y que contribuye poderosamente al despegue económico de Barcelona, beneficiada por las rentas obtenidas en esta zona por barones y eclesiásticos del entorno barcelonés (Sabaté, 2017: 89-90). La casa condal, que ha incorporado Piera en 1063, extrae e incrementa gracias a sus bailes numerosas y destacadas rentas y mantiene el castillo entre sus residencias (Bisson, 1984: 208).

Sobre esta base, en el siglo XII Piera consolida su mercado, celebrado en una planicie a las afueras del núcleo castral y eclesiástico, con suficiente pujanza y estabilidad para desarrollar un núcleo de casas, el Mercadal, objeto de la recaudación del diezmo tanto de estas viviendas como de los productos del mercado (Mas, 1909: 140). En estos momentos, en el término de Piera se documenta una veintena de lugares definidos como mansos, algunos de ellos con una extensión menor a la descrita en el siglo precedente. A falta de excavaciones arqueológicas, los indicios documentales avalan la separación en ellos entre el espacio animal y el humano - este último de mayor complejidad (con más de una estancia)- y muestran diferencias mutuas que se pueden relacionar con diversos niveles de riqueza y que reflejan la introducción de las mejoras consolidadas en Cataluña en el siguiente siglo (Bolós, 1996: 147-148; Riu, 1989: 46-51). Estos mansos funcionan a modo de unidades de explotación agropecuaria, porque cada uno articula uno o dos campos extensos, otros terrenos menores, a menudo fragmentos de bosque y cuenta con un policultivo, que incluye excedentes específicos, como la viña dirigida a la comercialización en el mismo siglo XII. Los mansos en este momento ocupan la zona más irrigada y la menos montañosa, y no articulan el conjunto del espacio agrario, porque no se delimitan mutuamente, sino que se intercalan entre otros terrenos y piezas de tierra agraria.

4. Petrus Damianus, Vita S. Romualdi, Patrologia latina Database, vol. 144, col. 961. 
Los mansos no son unidades estables: incorporan piezas de tierra e incrementan su espacio agrario, especialmente escalando en las zonas montañosas. Se participa, en el mismo siglo XII, en un denso mercado de tierras, en el que toman parte propietarios del lugar y cenobios (especialmente los que ya gozan de una fuerte presencia en la zona, como Sant Cugat y Montserrat), y también de capital: la mitad del manso Secafigues está en 1160 en prenda por un préstamo, por ejemplo. Siete mansos forman parte del dominio condal, y dos muy destacados pertenecen a la parroquia. A la vez, existe una notoria propiedad alodial, en algunos casos en manos de propietarios de mansos que residen en ellos y constan sus actividades de mejora antes de cerrar el siglo, como los Dorca, Caufí, Soler y Casalroig. La apetencia de los cenobios se centra en acaparar dominios eminentes (aplicando a veces diversas presiones), que a la vez garantizan la continuidad de los donantes, quienes restan con el dominio útil, lo que estabiliza fórmulas de doble dominio: «proienie sive posterite vestre uni post alium indivisibiliter mansum nostrum» (Rius, 1947: 196). Otros inversores se incrustan en la cadena de tenentes tras adquirir derechos sobre propiedades (Sabaté, 1992: 182), entre los que destacan de modo creciente inversores de la misma villa. Las fórmulas censuales, bajo clara definición enfitéutica (Viader, 1995-1996: 147-165) articulan estas relaciones y perfilan un escenario más complejo y dinámico para el manso que la específica relación de extracción de renta entre señor y campesino (To, 1993: 151-177), dada la inextricable incidencia plural de estímulos, sobre todo la villa y su mercado de tierra y de inversiones urbanas (Aventín, 1998: 80-83).

Antes de cerrar el siglo XII, la complejidad social es evidente. Los Agulló poseen alodialmente su propiedad, pero a la vez cultivan tierras de otros propietarios, sobre todo de la Iglesia, bajo formato enfitéutico. Las principales fortunas de la villa, como los Ferrer, Parellada o Saula, desarrollan una decidida opción terrateniente para invertir sus beneficios obtenidos, los primeros, de la herrería, y los otros, de sus servicios a la Iglesia como bailes. La tierra, sobre la que se pueden establecer perennes lazos censuales, es el valor seguro, sea propiedad rústica o urbana: los Amalric y la parroquia se benefician de la especulación en suelo urbano gracias al crecimiento físico de la villa. La pequeña baja nobleza local (los Folc, Pujades, Arbert de Fortesa, Barberà) se aboca al mismo tipo de inversiones, al igual que los castlanes de Piera se benefician de los censos procedentes de la edificación del espacio en torno al castillo. La mezcla de intereses e inversiones propiciará tensiones al cuajar la división estamental, al socaire precisamente del desarrollo urbano. Mientras en el siglo XII la prohomonia incluía hombres de villa, barones e incluso clérigos, al entrar en la centuria siguiente la asamblea general local ciñe los temas municipales a los primeros. Barones y clérigos mantendrán su presencia en la villa, pero su singularización estamental les permitirá eludir la contribución fiscal, lo que aportará tensiones en el siglo XIV, ante la palmaria contradicción de comportamiento cuando, por ejemplo, 
Arnau de Sau, Roger Sescorts y Pere de Torelló compartan inversiones siendo el primero doncel y los otros dos villanos.

El mercado local de Piera muestra una elevada presencia de vino, aceite y queso. No solo se condiciona la producción proveniente del entorno más inmediato, sino que la especulación por parte de los inversores urbanos irá orientando la producción en función de la demanda, como evidencia la expansión de la viña en el siglo XIII. Los contenidos de los mansos siguen oscilando y matizándose por la movilidad de un dinámico mercado de tierra. Su número crece espectacularmente, en parte por fragmentaciones y sobre todo por la elevada roturación de nuevas tierras, en espacios montañosos alejados de la villa y de otros núcleos, que comportan la edificación de un hábitat, lo que genera un nuevo manso. Esta dinámica explica que el monasterio de Montserrat acumule «viginti duos mansos vulgariter nuncupatos de Malcavaller» en esta cuadra que posee desde 1209 en el vecino término de Pierola y que enlaza con el llano central de Piera (Ribas, 1997: 161). Piera supera el centenar de mansos al entrar en el siglo XIv. Coherentemente, en 1322 se afirma que gran parte de su población habita en mansos: «ipsi vel magna pars eorum habitant in diversis et separatis mansis» ${ }^{5}$.

\section{LA VILLA SOBRE EL ESPACIO AGRARIO Y EL INCREMENTO DE EXACCIONES}

En coherencia con la dinámica generalizada en Cataluña, en el siglo XIII, y prosiguiendo la tendencia establecida en la centuria precedente, las cúpulas urbanas invierten en propiedades y se benefician del sistema enfitéutico (Bensch, 1989: 316). El vínculo censual facilita alargar la cadena de poseedores. Tanto Montserrat como Sant Cugat ceden bajo censo propiedades a personalidades de la villa de Piera (juristas, notarios, mercaderes), quienes subarriendan enfitéuticamente el trabajo en una cadena que se va alargando. De modo similar, una familia muy destacada, los Suau, paga el correspondiente censo a la Corona por el disfrute de varias tierras del monarca y, por supuesto, no pasan a cultivarlas personalmente, sino a establecerlas también a censo ${ }^{6}$. Las grandes familias locales van invirtiendo en propiedades, como los Roig, asentados en la escribanía o los Matoses y los Marganell, enriquecidos por la carnicería. Por su parte, la parroquia, en su dotación económica de 1260, incluye numerosas propiedades agrarias (huertos, viñas, piezas de tierra) y destacadamente tres mansos ${ }^{7}$.

5. Arxiu de la Corona d'Aragó (ACA), Cancillería, reg. 175, fol. 29v.

6. Arxiu del Monestir de Pedralbes (AMP), armario XVIII, libro 2, fol. 324v.

7. Arxiu Diocesà de Barcelona (ADB), Dotaliarum, vol. VII, fols. 249r-252r. 
La frecuente adquisición de parcelas de tierra dentro de los mansos por parte de inversores de la villa -con las posteriores negociaciones de su propiedad entre propietarios urbanos- fragmenta la unidad de propiedad del manso, pero no su percepción unitaria, sobre todo porque suelen seguir siendo trabajadas por los mismos campesinos, que en realidad van perdiendo progresivamente el control sobre su propiedad. Las donaciones piadosas remarcan la misma evolución: en 1320 Berenguer Rolf reconoce que tres piezas de su manso Grau las cultiva bajo dominio superior del beneficio de Santa Ana, en la parroquia de Piera ${ }^{8}$.

Las principales fortunas pierenses pronto invierten fuera de la villa, especialmente en Barcelona, atraídos por la especulación financiera (Bernat Descort en 1242 participa en los negocios bancarios del barcelonés David Campsor) y la actividad comercial mediterránea ${ }^{9}$. Muchos de ellos adquieren la ciudadanía barcelonesa, como Pere de Capellades, que ha destacado en el servicio de Jaime I y su segundogénito (Cruz, 1989: 179-185; 1997: 59-100), y otras familias establecen una rama en la capital del país, como los Claramunt en el siglo XIV y los Torelló en el XV. Pero todos ellos mantienen una intensa actividad sobre el campo de Piera, como da buena muestra Pere de Capellades al adquirir en 1271 mansos en Guinovard, La Riba y La Fortesa además de derechos sobre otros como el manso Maltorrent. En 1379 Pedro el Ceremonioso tiene que ordenar al baile que proceda contra los bienes poseídos por quienes, tras trasladar su domicilio fuera de la villa y especialmente a Barcelona, desatienden sus obligaciones fiscales en Piera ${ }^{10}$.

La pujanza de los ciudadanos de Barcelona se vuelca sobre el Vallés, por su inmediatez física, pero también sobre las regiones un poco más alejadas de Bages y Penedés, en una dinámica que incluye propiedades y jurisdicciones (Cuadrada, 1999: 172-198). En 1298 los barceloneses Durfort adquieren el señorío del vecino castillo termenado de Pierola, y en 1411 el ciudadano barcelonés Esperandéu de Cardona, que había sido vicecanciller del rey Martín, adquiere toda la jurisdicción sobre Piera ${ }^{11}$.

Los monasterios de Sant Cugat y Montserrat siguen estrategias programáticas en la adquisición de propiedades y mansos, como evidencia este último con su apetencia sobre los mansos de Maltorrent i d'en Pont, que incorpora en 1275. Estas posesiones permiten diversos niveles de especulación financiera. En 1320, Arbert de Freixe accede, a

\footnotetext{
8. AMP, armario XVIII, 2, fols. 409r, 416v-417r, 586r, 667r.

9. ACA, Cancillería, reg. 125, fol. $45 \mathrm{r}$.

10. ACA, Cancillería, reg. 807 , fols. $176 \mathrm{v}-177 \mathrm{r}$.

11. AMP, armario XXIII, leg. P, núm. 182.
} 
cambio de un elevado derecho de entrada que encubre un crédito, a un gran conjunto de mansos en Piera y términos vecinos mediante un trato enfitéutico que supone su incrustación, bajo el prior y la comunidad de Montserrat, en la cadena de poseedores por encima del trabajo agrario y en unas condiciones que el cenobio obligará posteriormente a revisar. El resumen del acuerdo inicial, redactado siglos después por Benet de Ribas, indica que Arbert de Freixe había recibido las propiedades «en feudo» de parte del prior de Montserrat quien, como posesor alodial, puede "establecer y dar en emphiteusis qualquiera mansos, tierras y possesiones", usando así la dicotomía popularmente asumida que resumía la tenencia en alodio o en feudo, reservando la primera a la plena propiedad (Ribas, 1997: 154).

Toda esta dinámica explica que al llegar a finales del siglo XIII el espacio agrario sea muy denso, haya disminuido la propiedad alodial, la mayoría de los campesinos sean en gran parte censatarios y que los vínculos enfitéuticos sirvan para incrementar la presión exactiva en una cadena de tenentes alargada, donde a menudo los señores directos exigen derechos recaudatorios y vinculantes sobre el campesino, concordando así con un incremento de la tensión en torno a las exacciones exigidas en gran parte de Cataluña (Benito, 2001: 122-123).

La carga exactiva parte del emblemático censo, ya sea el habitual par de gallinas o de capones, o, si acaso, el cerdo -este es el caso del manso Guinovard-, siendo más inusual el cobro en moneda. Además, los campesinos deben cumplir con varias exigencias recaudatorias, según cada caso, pero que suelen incluir las exacciones propias del desarrollo feudal de los siglos XI y XII (Sabaté, 2007: 97-115), como la emblemática tasca-cuya percepción inicialmente definía al propietario eminente (Feliu, 1996: 23)- y el braçatge, además del imprescindible diezmo castlán y de una elevada demanda por el locedo (lloçol), inicialmente relacionado con la herrería y erigido en el elemento más destacado y tenso de la escalada exactiva en la zona de Pierola y Piera en la segunda mitad del siglo XII (Sabaté, 1992: 206). La suma no es menor. En el vecino manso de Cocons, ya dentro del término de Pierola, en 1234 el locedo se define en "tres quarteras bladii terciencha de spella et pro acculeys mediam pugnam frumenti et mediam pugnam ordei et unum quarterium de vino et unam gallinam» (Rius, 1947: 435).

Los poseedores del dominio directo en estos momentos reclaman el cumplimiento de distintas exacciones que consideran que se han relajado indebidamente, sobre todo servicios y prestaciones como las joves y las batudes exigidas a unos campesinos situados en el dominio útil de diversos mansos, que invocan una tradición contraria. La dicotomía no se sitúa entre opresión de barones feudales y libertades urbanas, porque los que plantean las exigencias de unos derechos de origen feudal son los poseedores del 
dominio directo, residentes en la villa de Piera y concordantes en unos mismos objetivos, tanto si se trata de caballeros como de simples villanos: «tam filii militum quam etiam quarundam hominum dicte ville». Al mismo tiempo se pretende la adaptación de las exacciones a moneda ${ }^{12}$ y porciones de cosecha, especialmente trigo («pecunia vel blado vel aliis rebus») ${ }^{13}$, reproduciendo tensiones similares a las existentes en otros lugares de Cataluña (Fernández i Trabal, 1995: 195-205; Freedman, 1988: 67; Sabaté, 1993: 200)

En 1322 la universidad de los hombres de Piera solicita el apoyo real para los hombres que viven en mansos, porque los barones y villanos residentes en la villa posesores del dominio directo les han incrementado la exigencia de servitia et acapita, no dudando en dañar a las personas y bienes de quienes se niegan a aportar la prestación exigida. En respuesta, el monarca ordena al baile de Piera proteger los mansos contra unas pretensiones no suficientemente justificadas ${ }^{14}$.

La dinámica de acumulación de derechos y rentas aboca a una amplia variedad y casuística. Es de mencionar la evolución del derecho de jova adquirido por Guillem Batlle y compartido con su hijo en el año 1279 respecto a «tota iova termini et ville Apiarie quam habemus recipere debemus ratione peraliate quam per dictum regem habemus» ${ }^{15}$. La posterior herencia del titular de estos derechos abre unas ramificaciones que se convierten en el mejor paradigma de la especulación por parte de los hombres de la villa sobre la propiedad y los derechos de cualquier procedencia. La larga relación de los «aliis qui se dicunt habere partem in iova predicta» incluye familias tan notorias en la villa pierense como los Sescorts, además de otras como los Puigborràs, Basset o Bages ${ }^{16}$. Sobre esta base, las divergencias surgidas con los numerosos campesinos afectados por las exigencias recaudatorias justifican que se reclame una atención específica al monarca, coincidiendo con la anterior protesta. Con estas actuaciones, los hombres de los mansos demuestran disfrutar de suficiente número y organización para obtener de la universitas de Piera ${ }^{17}$ el mismo trato con que en 1320, justo poco después de retornar a la jurisdicción real, "pro parte proborum hominum et universitatis ville», se solicitaba al rey la revocación del diezmo castlán sobre el ganado de engorde aldeano ("decimum quod edulis sive capritis et porcellis quos nutriebat intus villam»). Se alegaba que este no se exigía antes del do-

12. ACA, Cancillería, reg. 246, fol. $332 \mathrm{v}$.

13. ACA, Cancillería, reg. 175, fol. $29 \mathrm{v}$.

14. ACA, Cancillería, reg. 175, fol. $29 \mathrm{v}$.

15. AMP, Pergaminos, armario XIII, núm. 633.

16. ACA, Cancillería, reg. 175, fol. 179r-v.

17. Arxiu Parroquial de Piera (APP), reg. 1, sin numerar. 
minio del vizconde de Cardona iniciado en $1296^{18}$, lo que el monarca acepta, invocando respetar la tradición de sus antecesores ${ }^{19}$.

En julio del mismo 1322, cuatro pierenses, en nombre propio y en procuración de otros, pues son muchos los afectados, solicitan la intervención del rey en el conflicto con los herederos de Guillem Batlle por las reclamaciones super iova et batuda, que ha derivado en acusaciones sobre la veracidad de las pruebas documentales contrapuestas, con el baile real aplicando detenciones y exigiendo fianzas. El soberano delegará en el jurista Ramon Coaner, práctica usual pero que levanta suspicacias por tratarse de un habitante de Piera y, por ello, considerado próximo a los hombres de la villa. Los más afectados y, al mismo tiempo, procuradores de los hombres de los mansos involucrados, son Borràs Perera, Berenguer Gabiol, Guillem Girbert y Romeu Riba. En ellos y en otros a menudo emparentados, como los Gabriel y los Orpí, descansa la movilización rural. Son las familias más notorias "de fuera de la villa", en su mayoría alodiales o que compatibilizan tratos enfitéuticos con destacados dominios propios, incrementados con sus particulares estrategias de inversión y acaparación. El vigor de encabezar una oposición a la presión de las familias de la villa no surge, pues, de la suma de campesinos desfavorecidos, sino de la capacidad del espacio rural de articular el propio peso mediante una estructura propia, con la debida estratigrafía social.

Esta articulación específica se irá erosionando por la colisión -o la coincidencia-con la emergencia de la estructura de la sociedad villana. El afianzamiento de una cúpula social que asienta sus bases en la acaparación de derechos y rentas teje diversos nexos de dependencia sobre el territorio de influencia. Esto explica que sean los mismos habitantes de los mansos de Piera que en 1322 se habían beneficiado de la reducción de las exigencias en servitia et acapita quienes en 1333 soliciten una derogación para cuando afecte a servicios acordados en el contexto de parentela seu amicitia ${ }^{20}$. Los vínculos de amistad son fácilmente justificables por la fractura de bandos o, también, por devoción hacia cenobios concretos, mientras que los de parentesco aumentan porque las principales ramas de destacadas familias de procedencia rural también van asentándose en la villa, en una línea que no hará más que incrementarse. No deja de ser, por tanto, un modo de poner de manifiesto, por parte de la sociedad rural, la aceptación de la superioridad de la villa.

Ya antes de cerrar el siglo XIII, se viven en Piera discusiones por la exigencia de los llamados malos usos y la sujeción de los hombres propios a la tierra. La vinculación del cam-

18. ACA, Cancillería, pergaminos de Jaime II, carpeta 143, núm. 728 .

19. ACA, Cancillería, reg. 218, fol. 154r-v.

20. ACA, Cancillería, reg. 462, fol. 23r-v. 
pesinado enfitéutico a la respectiva explotación agrícola (Pons, 1985-1986: 414-415) se impone sobre todo en los establecimientos nuevos o revisados. Es emblemática la actuación de un monasterio tan identificado con la élite burguesa barcelonesa como el de Pedralbes, que desde su fundación en 1326 cuenta por donación real con Piera como una de sus bases rentísticas (Castellano, 1998; 79-81). Superando las discrepancias locales gracias al apoyo regio ${ }^{21}$, el cenobio avanza en la acumulación de derechos y propiedades y en una gestión que pretende su máxima rentabilidad, lo que incide en la presión recaudatoria y la dependencia jurídica del campesinado ${ }^{22}$. Se ven afectados derechos sobre la producción y el comercio (diezmos, lezdas, peso, medidas, mercado...) y propiedades urbanas y rústicas, a menudo bajo fórmulas enfitéuticas que permiten exigir censos y laudemios, así como los derechos tradiciones (tasca, terrazgos, braçatge...), al tratar de obtener su traslación en moneda y aplicar un insistente recuento, motivo de diversas discusiones, que afectará a numerosos mansos y a unas doscientas piezas de tierra, además de entrar en conflicto con derechos alegados por destacados personajes de la villa.

La dinámica concuerda con la coetánea consolidación de las élites urbanas en todo el país. El protagonismo de los hombres de la villa de Piera ha absorbido unos intereses económicos urbanos y rurales y se ha apropiado de la representatividad del colectivo. Las peticiones y negociaciones con la Corona en la segunda mitad del siglo XIII muestran la capacidad organizativa de la universitas pierense y reflejan la vía de consolidación de la élite dirigente. Así se evidencia en la composición, en 1296, de la comisión de nueve villanos escogidos por los ochenta y cinco cabezas de familia que han participado en la asamblea para negociar las garantías con que aceptar el cambio de jurisdicción; o en las comisiones iniciadas en nombre de la universitas de Piera a partir de 1320, a raíz de la reintegración a la Corona real. La línea culmina en 1324 al reconocer el rey el consejo municipal de Piera, encabezado por los jurados ${ }^{23}$.

El nuevo gobierno municipal asume la representación local, la reivindicación de nuevos privilegios, el ordenamiento interno y, también, la redistribución de las exigencias fiscales comunes. El control de la magistratura municipal se convierte en un nuevo escenario donde se encontrarán los hombres de la villa y los hombres de fuera de la villa.

21. ACA, Cancillería, reg. 436, fol. 84r-v.

22. AMP, armario XIII, perg. 702.

23. ACA, Cancillería, reg. 230, fol. 230r. 


\section{DISTRIBUCIÓN DE LA CARGA FISCAL Y DEFENSIVA}

En el siglo XIII las necesidades defensivas en un contexto de tensiones entre la Corona y diversos barones, con los corolarios enfrentamientos jurisdiccionales y las respuestas unitarias a las demandas recaudatorias reales, afianzan la noción colectiva de los habitantes de Piera. Estos se agrupan y escogen a sus propios representantes para negociar con el monarca la concesión de los privilegios que deben favorecer el desarrollo de Piera a nivel social, económico y de garantías personales. Las implicaciones siempre son múltiples. Obtener de Jaime I, en 1274, que los pierenses no sean juzgados fuera de la villa (Miret i Sans, 1918: 355) remarca no solo la cohesión local, sino también la noción de capitalidad y la significación del grupo dirigente que asume la representatividad. Esto no es incompatible con una nítida segmentación social, reconocida, en la penúltima década del mismo siglo, entre mayores, medianos y menores.

Las exigencias fiscales de Pedro el Grande generan una amplia contestación (Ramos, 1993: 88-89), pero en el caso de Piera se erigen en el excipiente que provoca la confrontación interna. La incapacidad de la universitas local para distribuir la carga exactiva se eleva al monarca, quien delega en el reconocido jurista Ferrer de Manresa, con amplia experiencia en dictaminar en la corte real sobre problemáticas jurisdiccionales y locales $^{24}$. Este impone que en Piera las demandas de «questie, cene, albergue et exercituum, redemptiones vel alie exactiones quecumque fieretur tallia et collecta", exigidas por la Corona, se satisfagan mediante una distribución de la carga fiscal entre el conjunto de la población «a sou e liura» ${ }^{25}$, es decir, una carga proporcional a la riqueza de cada cual, lo que implica la confección de estimacions donde manifestar la riqueza respectiva ${ }^{26}$, que dan lugar a los «libros de manifiestos y estimas del común» ${ }^{27}$. La equidad que supere la fragmentación social exige que la tasación se lleve a cabo con la participación de miembros de las tres manos escogidos por el colectivo local ${ }^{28}$.

Se trata de un sistema de distribución interna de la carga recaudatoria coherente con la coetánea práctica en otras muchas villas (Turull, 1990: 493-494) dentro del marco mediterráneo (Wolff, 1956; Grohmann, 1986: 62), pero que desagrada a una cúpula social que, ocupada en acumular propiedades, derechos y rentas, considera injusto, desde el esquema enfitéutico usual, un planteamiento que grave al poseedor del dominio directo en

24. ACA, Cancillería, reg. 20, fol. 233r.

25. ACA, Cancillería, reg. 175, fol. 29v.

26. Arxiu Particular de Can Parellada (ACP), Speculum, 2.

27. ACA, Reial Patrimoni, Batllia General, reg. 874, fol. $15 \mathrm{v}$.

28. ACA, Cancillería, reg. 175, fols. 29v-30r. 
vez de al detentador del dominio útil. Este criterio opuesto puede imponerse con facilidad en Piera en el año 1296: el arbitraje de Ferrer de Manresa afectaba a las exacciones reales, pero, al cambiar de jurisdicción, el monarca pierde la capacidad recaudatoria, que pasará a ser ejercida por el nuevo señor, el vizconde de Cardona. Tras retornar al dominio regio en 1320, la universitas de Piera solicita volver a la anterior proporcionalidad «per solidum atque libram", tal como acepta Jaime $\mathrm{II}^{29}$, que a la vez reconoce la oposición de un sector de la villa a esta medida ${ }^{30}$. La presión recaudatoria y la proporcionalidad en las tallas se interpretan como expresiones de una común tensión entre la villa y el entorno rural, y, por ello, ambos temas fueron tratados ante la Corona por una misma comisión constituida por un hombre de la villa, Arnau de Tous, y otro del término, Berenguer de Gabiol.

En estos momentos, una reordenada questia pretende centrar la relación fiscal entre la Corona y los municipios (Sabaté, 1997: 424), lo que explica que Jaime II mencione explícitamente la aplicación de este sistema proporcional en la recaudación de las questies en Piera. En la práctica, cada aplicación del sistema recaudatorio renueva las divergencias y las tensiones, como experimenta el gobierno municipal estabilizado en 1324 al asumir la representatividad colectiva y la responsabilidad de aplicar las distintas tallas. Las actuaciones de los magistrados no solo no calman las discrepancias, sino que las agudizan, porque se alinean con la cúpula villana crítica hacia el sistema de sou e lliura, lo que no deja de denotar quién controla realmente el gobierno municipal y retiene la representatividad. En realidad, determinar que la división se haga a sou e lliura abre muchas brechas, empezando por el porcentaje que debe otorgarse a los bienes inmuebles y muebles y siguiendo con la respectiva valoración. Las acusaciones de irregularidades y de fraudes van lastrando y cuestionando todo el proceso. En 1328, el malestar obliga a que Alfonso el Benigno ordene revisar la talla efectuada en Piera para cubrir los 4.000 sueldos exigidos por la questia ${ }^{31}$.

El sistema de distribución proporcional basado en la valoración de la riqueza personal, en realidad, está siendo discutido coetáneamente en muchos lugares no solo por las tensiones y dificultades en la tasación de los bienes respectivos, sino porque a menudo parece penalizar las prácticas de inversión habituales, sin tener en cuenta la verdadera liquidez de los declarantes. En una sociedad en que la adquisición de propiedades y derechos y su transformación en renta censual se ha convertido en una vía para asegurar las ganancias de distinta procedencia, el número de los que se pueden consi-

29. ACA, Cancillería, reg. 428 , fol. $274 \mathrm{v}$.

30. ACA, Cancillería, reg. 175, fol. 29v.

31. Arxiu Comarcal de l'Anoia (ACAN), arxiu parroquial, fons notarial, 35/2, sin numerar. 
derar gravados en exceso puede extenderse más allá de las capas estrictamente superiores (Cammarosano, 1997: 82). En Piera, este proceso avanza hacia una fractura topográfica, al colocar mayoritariamente a unos en la villa y a otros en los mansos, porque los primeros se verán más afectados si la base fiscal se cierne sobre los poseedores del dominio directo.

En esta pugna entre los hombres de la villa y los de fuera de la villa, los primeros acaparan en gran parte la representatividad común, y así inciden en fijar la proporcionalidad recaudatoria que consideran adecuada para corregir las desviaciones que a su juicio produciría una aplicación solo fijada en el dominio directo. Al alterarse la proporcionalidad en las tallas, los hombres de fuera de la villa se consideran perjudicados por los de la villa, incluidos los magistrados municipales. Por ello en 1333 los hombres de los mansos ("pro parte hominum nostrorum comorantium in termino ville predicte in diversis mansis separatis») elevan una queja al rey contra el sistema de talla para recaudar la questia y otras exacciones reales dispuesto por los jurados ${ }^{32}$. Las tramas se enredan en un mismo contexto, por lo que se singularizan los servicios que los hombres de los mansos formalmente efectuarían gratis et ex magna liberalitate, que el soberano acepta eximir de la actuación de los recaudadores de questias ${ }^{33}$. La discrepancia sobre el método de cómputo fiscal, tensa en diferentes lugares de Cataluña, en Piera se prolonga en la pugna entre los hombre de la villa y los del término, tal como explicita Pedro el Ceremonioso cuando, nada más alcanzar el trono en 1336, tiene que intervenir para mostrar su coincidencia con los posicionamientos adoptados por sus predecesores: «dicte questie et alie exactiones regie per solidum et libram» ${ }^{34}$.

De todos modos, el impacto abierto en 1348 conduce al gobierno municipal a solicitar de la Corona una revisión de toda la carga fiscal. Se deriva, en 1350, la reducción de la questia y la anulación de la cena, aunque matizada temporalmente al año siguiente, justo cuando se negocian y redefinen las imposiciones y cuando se va acentuando el acceso a la deuda pública para hacer frente a una escalada de exigencias regias, que incluyen peticiones extraordinarias, maridajes y varias cenas de presencia, tanto del soberano como del primogénito en su posición de gobernador general. Esta polarización se agudiza, también en Piera, a raíz del contencioso generalizado, especialmente en la antepenúltima década del siglo XIV, en torno a la construcción y reforma de las murallas urbanas, las cuales, dentro de un marco de jurisdicciones infranqueables, disputas de capitalidad y temor a las incursiones exteriores, deben proteger a la propia población y a la existente en el

32. ACA, Cancillería, reg. 462 , fol. $22 \mathrm{v}$.

33. ACA, Cancillería, reg. 462 , fol. $23 \mathrm{r}$.

34. ACA, Cancillería, reg. 858 , fol. 12 r. 
campo, a pesar de sus propias discrepancias y el elevado coste de las obras, que en toda Cataluña contribuyen al fuerte endeudamiento municipal (Sabaté, 1997: 431-434).

Ultra las discrepancias internas respecto del coste de las obras, en todas partes se genera una específica tensión con el espacio circundante que formalmente se quiere proteger, con intervención de los oficiales jurisdiccionales. En Piera estas discusiones se viven dentro del propio término. A pesar de que la preocupación defensiva ya se expresa en 1336, el empeño por construir unas buenas defensas se acentúa por parte de los magistrados locales después de haber experimentado temores y dificultades debido a los tránsitos y depredaciones de tropas extranjeras en los años sesenta y setenta, sobre todo durante la travesía de la tropa castellana en 1363, el temor a que algunas companyes septentrionales se aproximen por la zona de Montserrat y el paso de las tropas de Jaime de Mallorca en 1374, que comporta la explícita orden real de recluir toda la población en el Mercadal ${ }^{35}$. Inmediatamente, en 1375, los hombres de los mansos y de los núcleos meridionales se enfrentan a las demandas del gobierno municipal, que pretende que todos los hombres del término contribuyan a la reconstrucción de las murallas de la Força de Dalt o Mercadal (《in Forcia Mercatalis ville Apiarie» ${ }^{36}$ ), infraestructura justificada para acoger en lugar seguro a toda la población de Piera. En contraposición, los hombres de fuera de la villa aprecian que el coste exigido es excesivo y que la lejanía dificulta que, en caso de verdadero peligro, se puedan refugiar en ella. Los núcleos meridionales habían desarrollado sistemas defensivos propios en La Fortesa, El Berdorc y, sobre todo, El Freixe, que aprovecha el propio recinto defensivo para remarcar una creciente singularización jurisdiccional.

La desconfianza se corresponde con la doble exigencia expresada por el gobierno municipal: en caso de peligro, la población incluida dentro del término castral de Piera debe refugiarse «in forcia Mercatallis» cargada con sus propias provisiones y bienes y, de acuerdo con esta protección, los hombres de fuera de la villa deben aportar los costes económicos en las obras de fortificación ${ }^{37}$. En coherencia con su gestión en otros lugares, el rey apoya el gobierno municipal y, por ello, en 1376 Pedro el Ceremonioso indica al capitán deVilafranca del Penedès que proceda contra los pierenses que se opongan a ambas obligaciones. La actuación deriva en el baile y subveguer de Piera ${ }^{38}$, revestido como capitán a partir de su designación, en 1375, como subdelegado y lugarteniente local del capitán del Penedès ${ }^{39}$. El baile, procedente de las familias dirigentes de la villa-como

35. ACA, Cancillería, reg. 1245, fols. 109v-110r.

36. ACA, Cancillería, reg. 791, fol. 89r-v

37. ACA, Cancillería, reg. 791 , fol. $89 \mathrm{v}$.

38. ACA, Cancillería, reg. 791, fol. 89r.

39. ACA, Cancillería, reg. 1253, fols. 70r-v. 
queda claro cuando la familia Sescorts retiene el cargo-, ejemplifica el engarce entre los intereses urbanos y la invocación de la autoridad regia, como procuran las élites en las villas reales catalanas.

El capitán, baile y subveguer de Piera insiste en la insuficiencia del recinto de El Freixe, en un conflicto que en 1376 el rey dispone que dictamine el veguer de Barcelona, a modo de mediador ${ }^{40}$. La cesión de Piera en 1380 al siciliano Guillermo Ramon de Montcada explica el grave incidente de 1381, en que la jurisdicción sobre El Freixe enfrenta al baile señorial de la villa contra el subveguer del rey, quien en el nuevo contexto prefiere empequeñecer el término de Piera ${ }^{41}$. La cesión jurisdiccional de El Freixe en $1386^{42}$ consolida su singularización. Esta misma cesión jurisdiccional impide, jurídicamente, que las poblaciones de los otros núcleos puedan refugiarse en El Freixe a pesar de que la proximidad de este núcleo contrasta con la lejanía de la villa. Ninguno de estos lugares puede hacer valer alternativas defensivas propias, pues el castillo auxiliar de El Bedorc está en ruinas y tanto la casa fuerte de este núcleo como la de La Fortesa no cumplen las condiciones consideradas esenciales para la defensa colectiva, como el espacio abierto dentro de la muralla.

Consecuentemente, con la excepción de El Freixe, en el término de Piera, los distintos lugares y los hombres de los mansos se sitúan bajo el amparo común inherente a compartir una misma jurisdicción, con las consecuencias de tener que aceptar la protección ofrecida por la villa dentro de sus murallas y tener que contribuir a su financiación. Las negociaciones abiertas entre ambas partes concluyen rápidamente el mismo año de 1376, al acordar que dos terceras partes del coste sean aportadas por los habitantes de la villa y la tercera parte restante por los foráneos. Tan solo un año después, en 1377, los hombres de fuera de la villa son acusados de no aportar la cantidad pactada. Los afectados tratan de justificar sus dificultades de pago, y la causa llega hasta el monarca, lo que plasma una dicotomía bien clara: «pro parte proborum hominum Forcie Superioris seu Mercatalli contra homines forenses termini dicte ville» ${ }^{43}$. El monarca delega la resolución en Bernat Garrigues, quien es recibido con desconfianza por los hombres de fuera de la villa, porque, al tratarse de un reconocido jurista de la villa ${ }^{44}$, puede presumírsele una tendenciosidad. De hecho, la tensión se alarga y las posturas se enrocan en un contexto en que se van generalizando las dificultades financieras ${ }^{45}$.

40. ACA, Cancillería, reg. 784, fols. 179r, 199r.

41. ACA, Cancillería, reg. 937, fols. 65r-68v; reg. 1636, fols. $126 \mathrm{r}-\mathrm{v}$.

42. ACP, Speculum, 3.

43. ACA, Cancillería, reg. 790, fols. 176r, 186r.

44. ADB, Registres Comuns, 19, fol. 70r. 
La dualidad de Piera se expresa en la misma titulación de los representantes de la población, presentados como «los homens, síndichs e procuradors per la universitat de la vila e terme d'Apiera». Es la dicotomía recalcada en las distintas intervenciones, especialmente en materia recaudatoria. Cuando en 1377 debe implantarse el rediezmo, para conseguir fondos con que intentar pagar los plazos de la deuda pública, la comisión creada para su recaudación está formada por los jurados y ocho pierenses más, de los cuales dos deben proceder de entre los habitantes de fuera de la villa. Significativamente, los dos foráneos son un Gabiol (Francesc de Gabiol), como evidencia de la prolongación secular del peso de la familia, y un Orpí (Ramon Orpí), que demuestra la consolidación del encumbramiento familiar ${ }^{46}$.

Si bien la proporcionalidad en sí misma es un reconocimiento de la dualidad, el escaso peso de los hombres de fuera de villa (una cuarta parte de los representantes) concuerda con la evolución decadente de los mansos en un escenario presidido por la reducción de explotaciones, la búsqueda de fórmulas que retornen la viabilidad de las tierras y, en definitiva, la prosecución de las vías de acumulación en manos eclesiásticas y burguesas, ya se trate de villanos o de inversores foráneos, como los ciudadanos barceloneses y los cenobios como Pedralbes. Propiedad, producción, exacciones y gestión municipal se evidencian como arietes que, en momentos de dificultad no solo agrietan la posición de la ruralidad, sino que la sitúan a merced del núcleo urbano al que se han ido vinculando inextricablemente. Los habitantes de los mansos no pueden plantear una específica vía de superación, porque su propia cohesión interna se ha ido resquebrajando a medida que se consolidaba la irrupción urbana.

\section{EL PESO DE LAS DIFICULTADES Y LA COHESIÓN DE LA OLIGARQUÍA DIRIGENTE}

El trastorno demográfico padecido a partir de mediados del siglo XIV se refleja en la morfología urbana de la villa por el elevado número de casas abandonadas, que obliga en 1357 al gobierno municipal a intervenir, por razones defensivas, fiscales e incluso de imagen de la villa ${ }^{47}$. Se pretende preservar el Mercadal, que afianza su centralidad y donde, en la segunda mitad de la centuria, se van asentando la mayoría de las familias destacadas. En el término, los pequeños núcleos evidencian la disminución de su peso demográfico, pero, sobre todo, del vigor social y económico de su población.

45. APP, reg. 2, sin numerar.

46. ACA, Cancillería, reg. 930, fol. 160v.

47. ACAN, arxiu parroquial, fons notarial, 88/3, sin numerar. 
En el espacio rural el número de propiedades se reduce drásticamente, si se compara con el elevado número de propiedades y mansos establecidos en el siglo anterior. En los años cincuenta y sesenta diversos mansos manifiestan la imposibilidad de aportar los pagos ordinariamente exigidos, y en los setenta, especialmente a partir de 1374, destacados habitantes del término consiguen que el mismo rey dicte una moratoria de sus deudas, como también conseguirán diversos habitantes de la villa a lo largo de la década ${ }^{48}$. El número más elevado de mansos abandonados (masos rònecs) afecta a explotaciones puestas en marcha en el siglo anterior, y con mayor incidencia en la zona montañosa que en la llanura fluvial. En esta, las negociaciones y moratorias de deudas pretenden prolongar la viabilidad de mansos y propietarios asentados en los núcleos, mientras las sucesiones y transacciones reflejan vacíos sobrevenidos. La casuística es variada y relacionada con las infraestructuras: el manso d'en Corts está derruido, pero esto no impide que sus tierras se pongan en cultivo de cereal en 1387 bajo censo y que los monasterios de Montserrat y Pedralbes disputen los derechos sobre el molino de aceite situado en $e^{49}{ }^{49}$ Las cesiones, ventas, fusiones de unidades de explotación y negociaciones contractuales evidencian un activo mercado de la tierra. Más que el abandono, destaca la acentuación en la acaparación de propiedades. La historiografía sitúa en el siglo XIV la estabilización del manso en el centro del campo catalán (Aventín, 1996: 145). Propiamente en Piera, se estabiliza una estratigrafía, con repercusiones seculares, que define la viabilidad y consolidación de determinados mansos. Se benefician y afianzan mansos que ya aportaban una base y un recorrido destacados, como los Orpí, si bien algunas familias que habían sido muy importantes certifican, en este contexto, una posición menguante. Se acentúa la penetración de los hombres de la villa en el espacio rural. Prácticamente todas las familias de la élite de Piera con rastro notarial en esta cronología incrementan su patrimonio aprovechando los diversos vacíos, que, por razones variadas, se han producido en el entorno rural inmediato. La disminución de mansos reduce unidades de hábitat en el campo, pero los espacios de explotación, de forma conjunta o fragmentando piezas de tierra, van siendo incorporados en el sistema productivo, como en otros lugares de Cataluña (Ferrer, 2001: 189-212). También concuerda el incremento de contratación temporal (a lauraó) liberada de otras cargas (Donat, 1999: 128), que se suma a la creciente presencia de arrendamientos temporales de piezas de tierra durante las décadas precedentes, tendencia que se acentuará a lo largo de la segunda mitad del siglo XIV. El sistema fiscal se adapta a la realidad: en 1377 el cobro del rediezmo incluye a cualquiera "qui lauraons haia dins la vila o terme» ${ }^{50}$.

48. ACA, Cancillería, reg. 774, fols. 18v-184r, 188v; reg. 775, fols. 13r-v; reg. 783, fols. 97r-v.

49. AMP, armario XXIII, leg. P, núm. 182.

50. ACA, Cancillería, reg. 930. fol. 160 r. 
La acaparación de propiedades conseguida por las principales familias de la villa (Sescorts, Claramunt, Matoses) preside una alargada estratigrafía en la que la riqueza se visualiza sumando dominios directos, diversos niveles de posesión en el dominio útil y derechos de variada índole. Las fórmulas censuales y las contrataciones facilitan numerosas combinaciones. También una elevada movilidad. En 1344 Ramon Gras arrienda por nueve años una pieza de tierra del manso Baró situado en el vecino término de Masquefa, teniendo que asumir el censo anual con que está gravada. Similarmente, población del entorno accede al trabajo de piezas de tierra en mansos ubicados en Piera ${ }^{51}$. Sobre todo, destacados forasteros adquieren aquí propiedades, como es el caso de ciudadanos barceloneses, y cenobios como Montserrat y Pedralbes. El primero mantiene, desde su proximidad, una permanente presencia, y el segundo, tras llegar en 1326, rentabiliza sus posesiones e incrementa el patrimonio, bien gestionado por su procurador, atento a los diferentes «iuris alodialis mansorum» ${ }^{52}$ y a precisar, en cada transacción, los derechos poseídos, como emblemáticamente se lleva a cabo en $1411^{53}$.

La tipología productiva se adapta a la demanda del mercado. Aun manteniendo una notoria presencia de viña y también del roldón ${ }^{54}$, destaca el aumento de cereal panificable (trigo candeal y, muy por encima de este, avena, espelta y, sobre todo, cebada) y el contundente incremento del aceite, tendencias acentuadas en el siglo XV que concuerdan con la coetánea evolución en Cataluña. Significativamente, el rediezmo establecido en 1377 especifica que, por lo que respecta a la producción agraria, grava «tots blats e venema, roudor, olives, nous, avelanes, cànem, li, çebes, ayls e de cols e de porros» ${ }^{55}$. La demanda urbana incide en la importante venta de madera de pino procedente de la parte elevada del término y en la producción de azafrán. Esta ya se documenta y destaca en 1308 en los derechos sobre Piera que Jaime II cede a su esposa, la reina Elisenda ${ }^{56}$, participando de una zona de elevada productividad, entre Vilafranca del Penedés e Igualada, como será posteriormente reconocido cuando en el siglo XV el control fiscal ciña los mercados de su distribución (Verdés, 2001: 768-769).

La cesión del mero y mixto imperio de El Freixe a Berenguer de Tous en 1386 consolida su escisión jurisdiccional y fiscal respecto del castillo termenado de Piera, pero pone

51. AMP, armario XVIII, 2, fols. 397r-v, 416v.

52. ACA, Cancillería, reg. 794, fol. $96 \mathrm{v}$.

53. ACP, Speculum, 4.

54. APP, regs. 1, 2, sin numerar.

55. ACA, Cancillería, reg. 930, fol. 160r.

56. ACA, Cancillería, reg. 810, fol. 28v; AMP, Pergaminos, 558, 620, 792; AMP, armario XVIII, 2 , fols. 323r, 343r, 399r. 
en evidencia que gran parte de las propiedades del lugar están en manos de habitantes de la villa pierense, como los Sescort y los Claramunt. De todos modos, la capitalidad de servicios de la villa se matiza, porque, por ejemplo, algunos habitantes de El Freixe contratan crédito en la capital de la veguería, Vilafranca del Penedés. En cualquier caso, la singularización jurisdiccional de El Freixe aboca a un solapamiento de radios contrapuestos, porque el subveguer de Piera no puede intervenir en este lugar cuando se produzcan incumplimientos en las obligaciones contraídas por algunos de sus habitantes con propietarios o acreedores de Piera, un escenario habitual en las tensiones territoriales de la Cataluña bajomedieval.

La incidencia de la sociedad urbana sobre la población rural se percibe también en la actuación de los bandos. En todas las villas y ciudades, los mecanismos populares de respuesta a las tensiones y dificultades sociales se expresan mediante los vínculos de solidaridad basados en familiares y amigos que configuran los respectivos bandos. Su concatenación divide cada villa o ciudad en dos grupos enfrentados, por lo general bajo la presidencia de los mismos personajes que detentan el poder económico, e incide con naturalidad sobre la región de influencia. Ya a comienzos del siglo XIv, con una Piera fragmentada entre los Sescorts y los Comes, el posicionamiento de los Claramunt y los Suau al lado de los primeros, y de los Ferrer, los Argençola y los Canaletes entre los segundos, moviliza las respectivas cadenas de imbricación antropológica y afecta de lleno al entorno rural. De hecho, la coetánea exigencia recaudatoria por parte de los hombres de la villa se ejerce con mayor o menor presión según a qué bando se pertenezca, tal como se constata en torno a Romeu Sescorts, cuñado precisamente de Guillem Batlle, el receptor de la jova a partir de la que se generará el gran revuelo prolongado hasta los años veinte del siglo xIv, ya comentado ${ }^{57}$.

En este escenario, el espacio urbano y el rural se mezclan con creciente naturalidad. La intervención, en 1350, del portavoz en Cataluña del gobernador general contra Roger Sescorts ${ }^{58}$, facilita que en cierto modo el bando de los Sescorts dé el relevo a los Barberà, surgidos de su entorno y muy arraigados en el espacio rural, donde actuaban coaligados con otro linaje baronial, los Pujades. Coincidiendo con la evolución generalizada, los primeros golpes de crisis no son afrontados por los afectados a través de una respuesta de clase, sino mediante la búsqueda del apoyo inmediato del respectivo bando (Sabaté, 1997: 453-455). Las intervenciones del rey o su alto delegado han de repetirse entre 1353 y 1355 y las tensiones se recrudecen en la antepenúltima década, cuando los Sescorts vuelven a ser penalizados por el rey en 1374. De acuerdo con la tipología usual de violencia,

57. ACA, Cancillería, reg. 175, fols. 178v-179r.

58. ACA, Diversos, Fons institucionals, Governació General de Catalunya, reg. 1, hojas sueltas. 
se recurre sobre todo a la intimidación personal, el asalto de casas y mansos e incluso talas, como la padecida en 1382 por Joan Claramunt, quien recibirá un adecuado apoyo superior al encontrarse al servicio del primogénito real ${ }^{59}$. De este modo, la intersección entre las tensiones sociales y los bandos en la Piera de la segunda mitad del siglo XIV contribuye poderosamente a mezclar el espacio rural y el urbano, y a acentuar el protagonismo de este, dado que no deja de ser la sede de los caps de bàndol que presiden las facciones contrapuestas.

\section{LA SALIDA DE LA EDAD MEDIA}

En 1431 el monasterio de Pedralbes culmina su progresión en Piera al adquirir toda la jurisdicción ${ }^{60}$. Se mantienen fuera algunos derechos, como el locedo, que, fragmentado, irá pasando entre diversos particulares, algunos de la villa, otros de fuera, como Joan Torelló, platero y ciudadano barcelonés con raíces pierenses. El monarca retiene la cena y la questia regia. La percepción de esta genera una enorme controversia en 1437, con presión sobre los que alegan estar exentos. Finalmente, el gobierno municipal negocia con el rey su reducción, tal como obtiene en 1451 . De todos modos, las finanzas municipales avanzan hacia la bancarrota en 1459 , por lo que al año siguiente se solicita la intervención especial del rey. La búsqueda de soluciones particulares tensiona la élite: los Sescorts y los Claramunt persiguen, a lo largo del siglo desde 1420, un reconocimiento baronial que les libraría de contribuciones, por lo que se encuentran con la oposición del consejo municipal.

Diferentes familias en la villa han consolidado su preeminencia (Matoses, Ferrer) acumulando diversas inversiones. Escasas familias mantienen una posición destacada en el ámbito rural, como los Figuera de mas Grau. Muy significativamente, el siglo XV consolida la tendencia iniciada antes de cerrar la centuria precedente: los principales linajes del entorno rural han asentado una rama destacada en la villa, como los Mulner de La Fortesa, los Ferriol o incluso los Orpí. Estos asentamientos manifiestan, ante todo, un cambio de estrategia. Estos últimos, como ejemplo nítido, continúan siendo un referente con respecto a los mansos, con un destacado patrimonio alodial aún incrementado, pero al establecer una residencia en la villa aceptan la preeminencia de esta y de su entorno social. Se van alejando así las propuestas de cohesión y respuesta centradas exclusivamente en el ámbito rural y se busca el encaje en el mismo juego de poder centrado en la villa. La holgada posición de los Orpí les facilita una posición destacada e influyente que les permite participar de las magistraturas locales, incluida la juradería.

59. Arxiu de Can Ferrer del Coll (AFC), perg. 18b.

60. ACA, Cancillería, reg. 2648, fols. 19r-20v; AMP, perg. 551. 
$\mathrm{El}$ análisis regional pone de relieve la pérdida de peso de Piera, muy claramente respecto de la capital de la veguería,Vilafranca del Penedés, pero también respecto de la sede de la subveguería vecina aguas arriba del río Anoia, Igualada, tal como se aprecia con las contrataciones y obligaciones registradas en estas villas. La capitalidad superior de Barcelona se percibe en todos los aspectos: ya sea la devoción a la patrona de Barcelona, Santa Eulalia, a mediados del siglo XIv ${ }^{61}$, o la constatación de que en 1460 la mayoría de los acreedores de la villa tienen registrada su deuda en la capital del país. A pesar de que el fogaje de 1497 refleja la escasa demografía de los núcleos menores situados dentro del término de Piera (Iglésies, 1991: 221-222), estos han ido afianzando su propia singularidad, ya sea como parroquia (Sant Jaume Sesoliveres, con Santa Creu de Creixà como disputada sufraganea) o como cuadra (El Bedorch, La Fortesa). El Freixe, tras segregarse como término castral, remarca las relaciones con los términos castrales vecinos de Cabrera y Vallbona, con los que ahora comparte jurisdicción.

Las contrataciones temporales de parcelas y explotaciones penetran en el siglo xv, tal como también sucede en territorios próximos (Benito, 2003: 152). A la vez, ya en la segunda mitad del siglo XIV se incentivan las fórmulas enfitéuticas al entenderlas de mayor estabilidad (por ejemplo, en 1384 un grupo de rectores del decanato solicita al obispo permiso para que el decano de Piera, asistido por un consejo de clérigos, pueda establecer en enfiteusis las tierras y posesiones de los beneficios vacantes) ${ }^{62}$. En las primeras décadas del siglo XV se suceden nuevos contratos enfitéuticos que retratan la complejidad acumulada: en 1416 el ciudadano de Barcelona Jaume Morató establece, en Piera, su manso de la Grua al pierense Jaume Grau, propietario del manso de la Cabanya, teniendo que excluir una pieza del manso que no le pertenece, especificando la parte censual que corresponde al monasterio de Pedralbes y la que pertenece a Montserrat, y definiendo dos tipos de diezmos, el que le corresponde por las piezas alodiales y el reducido que afecta a las restantes ${ }^{63}$. La renovada estabilidad que se podría esperar por estos contratos topa con el escenario de la Cataluña de las primeras décadas del siglo Xv, donde los señores directos, pertenecientes a todos los estamentos, están preocupados por la pérdida de ingresos debida a la oscilación de los precios del grano y las alteraciones en la paridad de la moneda (Sabaté, 2004: 301). Ante esta situación, en Piera el monasterio de Pedralbes, reforzado al aunar el dominio jurisdiccional a sus dominios, plantea un pormenorizado recuento a fin de no perder ocasión para presionar al campesinado. El punto de partida es el vínculo enfitéutico que perfila la mayoría de los dominios mediante unas prestaciones basadas en los censos monetarios y el diezmo, y sin olvidar, en la medida de lo posi-

61. ADB, Speculum Titulorum Ecclesiasticorum, vol. IV, pp. 672-673.

62. ADB, Gratiarum, reg. 9, fols. 49v-50r.

63. AMP, armario XVIII, 2, fols. $417 \mathrm{r}-418 \mathrm{r}$. 
ble, cualquier prestación existente, como dirá el monasterio de Pedralbes al querer contabilizar «tots e sengles censos, rendes, censals, agrers, delmes, parts d'esplets, tasques, brassatges, directes e alodials sennories e altres qualsevol drets los quals lo dit monastir ha e reb e rebre ha acustumat en la dita vila de Piera, termens e territoris de aquella [...] axí en diners com en altre qualsevol spècie» ${ }^{64}$.

La presión incrementa la tensión en el espacio agrario, que se introduce en la problemática remensa. En 1448 Piera recibe la visita de Jaume Safont y Pau Messeguer «per los afers dels pagesos de remença» (Sans i Trave, 1994: 108) y en 1449 se incluye dentro de las actuaciones represivas del veguer deVilafranca ${ }^{65}$. La guerra civil, entre 1462 y 1472, agrava el malestar en el campo. En la antepenúltima década se efectúa un balance de la situación en el espacio rural de Piera que pone de manifiesto numerosos masos rònecs $\mathrm{y}$ una grave pérdida de exacciones. En 1480 el baile de Piera, en nombre de su señor, el monasterio de Pedralbes, emite un bando para que los herederos de los mansos arruinados y vacantes expongan sus derechos en un plazo de treinta días para que sean reconocidos en su posesión ${ }^{66}$. La viabilidad solo se afianza mediante revisiones progresivamente acordadas que van disminuyendo las exigencias. Así, por ejemplo, el notario barcelonés Berenguer Alemany recibía de los Valencià, por el manso Bou de Les Pujades, 12 sueldos y un par de pollos más el diezmo de los esquilmos, y a partir de la revisión de 1484, la viuda de Joan Valencià solo aportará 4 sueldos más el diezmo ${ }^{67}$.

Se llega a la salida del siglo con una cincuentena de mansos en funcionamiento, abandono de los peores terrenos en altitud y ubicación, presencia de dominios alodiales destacados, numerosas piezas de tierra arrendadas y un dominio directo mayoritariamente concentrado en cenobios y tenentes urbanos, de la propia villa o de capitales superiores como Barcelona. El campo ha perdido su capacidad de organizarse sobre sí mismo, pero también la villa ve reducir su capitalidad en el encaje global de Cataluña. Significativamente, a mediados del siglo XVI, el $60,6 \%$ de la población de Piera se declara campesina, lo que triplica el $20,67 \%$ propio de la vecina Igualada ${ }^{68}$, comparación en realidad poco adecuada porque, aunque ambas sean sedes subvicariales, la segunda destaca precisamente por la exigüidad de su término, lo que limita ostensiblemente su espacio agrario. La estructura dual de una Piera constituida por la villa y la población dispersa dentro de

64. Arxiu Particular Sanahuja-Romaní (ASR), Capibrevium Villae et Termini Apiaria (1503), fols. $1 \mathrm{r}-\mathrm{v}$.

65. ACP, Speculum 3.

66. AMP, armario XVIII, leg. P, núm. 182.

67. AMP, armario XVIII, libro 2 , fol. $422 \mathrm{v}$.

68. ACA, Fons notarials, districte d’Igualada, núm. 1043. 
su término se mantiene en la formalidad, que continuará hablando de «villae et termini Apiarie» ${ }^{69}$.

\section{CONCLUSIONES}

Piera plantea la singularidad, en el escenario territorial bajomedieval, de que los llamados a sí mismos hombres de fuera villa se articulen contra los hombres de la villa para quejarse, en los siglos XIII y XIV, de la presión exactiva y del reparto fiscal. El establecimiento del sistema agrario en los siglos x y XI ha avanzado en la progresiva implantación de sistemas de doble dominio, plenamente cuajados con la enfiteusis. Esta ha permitido diversas acumulaciones de derechos directos y, también, útiles, alargando la cadena de tenentes. La dinámica ha desembocado en una presión exactiva muy elevada a fines del siglo XIII, la cual ha puesto en evidencia un espacio rural que va perdiendo sus propios anclajes por la progresiva penetración de los intereses de cenobios y élites urbanas, que han interpretado el campo como su ámbito de inversión y especulación. Las dificultades surgidas en el siglo XIV incentivan contrataciones temporales que no empañan una visión de estabilidad ligada a la enfiteusis. En búsqueda de rentabilidad, los señores directos ejercen una presión sobre el espacio rural en el siglo XV que obligará a buscar nuevos acuerdos, dentro de un marco más globalizado que ha jerarquizado las capitales urbanas catalanas, dejando en una posición secundaria a núcleos como Piera.

\section{AGRADECIMIENTOS}

Agradezco a Pedro Barbado, Lluís Cifuentes, Gemma Escribà y Regina Sáinz de la Maza, que, bajo financiación del Ayuntamiento de Piera, participaron en el vaciado documental, así como los comentarios de los evaluadores externos e internos de Historia Agraria.

\section{REFERENCIAS}

AtTField, R. (2006). Environmenal Sensibility and Critiques of Sterwardship. En R. J. Berry (Ed.), Environmental Stewardship: Critical Perspectives: Past and Present (pp. 76-91). London/New York: T. X. Clack International.

Aventín, M. (1996). La societat rural a Catalunya em temps feudals:Vallès Oriental, segles XIII-XIV. Barcelona: Columna.

69. ASR, Capibrevium Villae et Termini Apiaria (1503), como paradigma más evidente. 
Aventín, M. (1998). Els masos a la baixa edat mitjana: Família pagesa, petita explotació i mercat. Quaderns, (19), 80-83.

Bensch, S. P. (1989). La primera crisis bancaria de Barcelona. Anuario de Estudios Medievales, (19), 311-327.

BENito, P. (2001). La formació de la gran tinença pagesa i la gènesi del mas com a estructura senyorial (segles XII-XIII). En M. T. FERRER I MALlol, J. MutgÉ IVIVES \& M. RIU I RIU (Eds.), El mas català durant l'edat mitjana i moderna (segles IX-XVIII) (pp. 103-124). Barcelona: CSIC.

Benito, P. (2003). Història Medieval. En F. SABATÉ (Ed.), Història deVilanova del Camí (pp. 91-205). Lleida: Pagès.

Bisson, T. N. (1984). Fiscal accounts of Catalonia under the early count-kings (11811213). 2 vols. Berkeley - Los Angeles - Londres: University of California Press.

Bolós, J. (Ed.) (1996). Un mas pirinenc medieval:Vilosoiu B (Cercs, Berguedà). Lleida: Universitat de Lleida.

Cammarosano, P. (1997). Il sistema fiscale delle città toscane nel tardo medioevo. En M. SÁNCHez \& A. Furió (Coords.), Col-loqui Corona, Municipis i Fiscalitat a la Baixa Edat Mitjana (pp. 79-87). Lleida: Institut d'Estudis Ilerdencs.

Castellano, A. (1998). Pedralbes a l'edat mitjana. Història d'un monestir femení. Barcelona: Publicacions de l'Abadia de Montserrat.

CoRRAl, J. L. (1984). El origen de las comunidades medievales aragonesas. Aragón en la Edad Media, (6), 67-94.

Cruz, J. (1989). Pere de Capellades, notari de la Cancelleria de l'infant Jaume, futur rei Jaume de Mallorques: Esbós biogràfic d'un funcionari del segle. En XIII Congrés d'Història de la Corona d'Aragó (Palma de Mallorca, setembre-octubre, 1987) (pp. 179.185). Palma: Institut d'Estudis Baleàrics.

CruZ, J. (1997). Una família de patricis anoiencs a la Catalunya baixmedieval: Pere de Capellades i els seus successors (segles XIII-Xv). Miscellanea Aqualatensia, (8), 59100.

CuAdrada, C. (1999). L'aixada i l'espasa: L'espai feudal a Catalunya. Tarragona: Arola. DonAT, L. (1999). Contractes "ad laborationem» i establiments de masos després de la pesta negra (1349). En R. Congost \& L. To, Homes, masos $i$ història: La Catalunya del nord-est (segles $x i$-xx) (pp. 125-149). Barcelona: Publicacions de l'Abadia de Montserrat.

Donat, L., Lluch, R., Mallorquí, E., Soldevila, X. \& To, L. (2001). Usos i abusos del concepte de mas: El cas de la regió de Girona (segles XIII-XIV). En M. T. FERRER I MALlol, J. MutgÉ I Vives \& M. Riu I Riu (Eds.), El mas català durant l'edat mitjana i moderna (segles IX-XVIII) (pp. 127-158). Barcelona: CSIC.

FALVeY, L. (2005). Religion and Agriculture: Sustainability in Christianity and Budhism. Netherlyh: The Institute for International Development. 
Feliu G. (1996). La pagesia catalana abans de la feudalització. Anuario de Estudios Medievales, 26 (1), 19-41.

Fernández i Trabal, J. (1995). Una familia catalana medieval. Els Bell-lloc de Giroan 1267-1533. Barcelona: Publicacions de l'Abadia de Montserrat.

FERRER, M.T. (2001). Establiments de masos després de la pesta negra. En M.T. FERRER i MAllol, J. MutGÉ I Vives \& M. RIU I RiU (Eds.), El mas català durant l'edat mitjana i moderna (segles IX-XVIII) (pp. 189-241). Barcelona: CSIC.

FreEdman, P. H. (1988). Assaig d'història de la pagesia catalana (segles XI-XV). Barcelona: Edicions 62.

GARCÍA DE CortázAR, J. A. (1988). Organización social del espacio: Propuesta de reflexión y anàlisis histórico de sus unidades en la España medieval. Studia Historica. Historia Medieval, (6), 195-236.

Grohmann, A. (1986). L'imposizione diretta nei comuni dell'Italia centrale nel XIII secolo: La Libra di Perugia del 1285. Roma: École Française de Rome.

IgLÉsIES, J. (1991). El fogatge de 1497. Barcelona: Fundació Salvador Vives Casajuana. JENKINs, W. (2008). Ecologies of Grace: Environmental Ethics and Christian Theology. Oxford: Oxford University Press.

Junyent, E. (1987). Diplomatari de la catedral de Vic: Segles IX-X. Vol. 4. Vic: Patronat d'Estudis Ausonencs.

MAS, J. (1909). Notes històriques del Bisbat de Barcelona. Vol. 3. Barcelona: Societat General d'Arts Gràfiques.

Miret i SANS, J. (1918). Itinerari de faume I el Conqueridor. Barcelona: Institut d'Estudis Catalans.

Pons, J. M. (1985-1986). Entre l'emfiteusi i el feudalisme (Els reculls de dret gironins). En J. PorTella (Ed.), La formació $i$ expansió del feudalisme català (1985-1986) (pp. 331-343). Girona: Col-legi Universitari de Girona/Universitat Autònoma de Barcelona.

Pons, J. M. (1989-2006). Reculls d'estudis d'Història jurídica catalana. 4 vols. Barcelona: Fundació Noguera.

RAMOS, M. L. (1993). Sobre alguns conflictes socials a Tarragona i comarques properes durant els primers anys de la dècada del 1280, a través de la documentació conservada a la Cancelleria Reial. Quaderns d'Història Tarraconense, (12), 67-94.

RiBAS, B. (1997). Annals de Montserrat (1258-1485). Barcelona: Curial Edicions Catalanes/Publicacions de l'Abadia de Montserrat.

Riv, M. (1989). L'arqueologia medieval a Catalunya. Sant Cugat del Vallès: Amelia Romero.

Rius, J. (1947). Cartulario de «Sant Cugat» del Vallés. Vol. 3. Barcelona: CSIC.

SABATÉ, F. (1992). Estructura socio-econòmica de l'Anoia (segles X-XIII). Acta Historica et Archaeologica Mediaevalia, (13), 175-238. 
SABATÉ, F. (1993). Les castlanies i la comissió reial de 1328. En M. SÁnchez (Ed.), Estudios sobre renta, fiscalidad y finanzas en la Cataluña bajomedieval (pp.177-242). Barcelona: CSIC.

SABATÉ, F. (1997). L'augment de l'exigència fiscal en els municipis catalans al segle XIV: Elements de pressió i de resposta. En M. SÁnCHEZ \& A. Furió (Coords.), Col·loqui Corona, Municipis $i$ Fiscalitat a la Baixa Edat Mitjana (pp. 423-465). Lleida: Institut d'Estudis Ilerdencs.

Sabaté, F. (1999). Història Medieval. En F. SABATÉ (Ed.), Història de Piera (pp. 110-253). Lleida: Pagès.

Sabaté, F. (2004). Història Medieval. En A. Balcells (Ed.), Història de Catalunya (pp. 99-334). Barcelona: L'Esfera dels Llibres.

SABATÉ, F. (2007). La feudalización de la sociedad catalana. Granada: Universidad de Granada.

SABATÉ, F. (2017). The Building of Territorial and Ideological Capital. Viator, 47 (1), 89120.

Sans i Travé, J. M. (1994). Dietaris de la Generalitat de Catalunya. Vol. 1. Barcelona: Departament de la Presidència de la Generalitat de Catalunya.

To, L. (1993). Le mas catalan du XII ${ }^{\mathrm{e}}$ s.: Genèse et évolution d'une structure d'encadrement et d'asservissement de la paysannerie. Cahiers de civilisation médiévale $X^{e}$ XII siècles, 36 (2), 151-177.

Turull, M. (1990). La configuració jurídica del municipi baix-medieval: Règim municipal i fiscalitat a Cervera entre 1182-1430. Barcelona: Fundació Noguera.

VERDÉs, P. (2001). Una espècie autòctona: El comerç del safrà a Catalunya durant el segle Xv. Anuario de Estudios Medievales, (31), 757-785.

VIADER, R. (1995-1996). Autour d'une pratique juridique: Les contracts agraires des Archives Capitulaires de Barcelona (XI'-XIII ${ }^{\mathrm{e}}$ siècle). Acta historica et archaeologica $\mathrm{Me}$ diaevalia, (16-17), 147-165.

WolfF, P. (1956). Les estimes toulousaines des XIV et XV siècles. Toulouse: Bibliothèque de l'Association Marc Bloch de Toulouse. 